\begin{tabular}{|c|c|c|c|}
\hline \multirow{3}{*}{$\begin{array}{r}\text { Case Reports in } \\
\text { Gastroenterology }\end{array}$} & \multirow{2}{*}{\multicolumn{2}{|c|}{ Case Rep Gastroenterol 2018;12:7-12 }} & \multirow[b]{3}{*}{ Oparger } \\
\hline & & & \\
\hline & $\begin{array}{l}\text { DOI: } 10.1159 / 000479496 \\
\text { Published online: January 17, } 2018\end{array}$ & $\begin{array}{l}\text { (C) } 2018 \text { The Author(s) } \\
\text { Published by S. Karger AG, Basel } \\
\text { www.karger.com/crg }\end{array}$ & \\
\hline & $\begin{array}{l}\text { This article is licensed under the } \\
\text { International License (CC BY-NC) } \\
\text { Usage and distribution for commerc }\end{array}$ & $\begin{array}{l}\text { nons Attribution-NonCommercial } 4.0 \\
\text { ger.com/Services/OpenAccessLicense). } \\
\text { uires written permission. }\end{array}$ & \\
\hline
\end{tabular}

\title{
Coexisting Granular Cell Tumor and Tubular Adenoma of the Ileocecal Valve
}

\author{
Jonathan Gapp John Gross Lakshmi Chintalacheruvu \\ Savio Reddymasu \\ Creighton University Medical Center, Omaha, NE, USA
}

\section{Keywords}

Granular cell tumor - Tubular adenoma - Ileocecal valve

\begin{abstract}
Granular cell tumors (GCTs) have been described as neoplasms of Schwann cell origin. They are often benign and notably uncommon in the gastrointestinal tract. Recently, their incidence has become more common, likely as a result of increased colonoscopy screenings. Very few data exist regarding their potential for malignancy, but malignant GCTs have been reported. Here, we report the case of a young female patient who was diagnosed with an atypical GCT on the ileocecal valve with an overlying tubular adenoma which was found incidentally on colonoscopy. This represents the first known report of a GCT with atypical features on the ileocecal valve, as well as a rare case of overlying adenomatous changes. Due to the paucity of cases, there is no clear modus operandi for their management. Furthermore, it is not clear whether surgical or endoscopic interventions or simple observation may be most appropriate. Further studies are needed to evaluate the potential for malignancy of this tumor, as well as its management.

(C) 2018 The Author(s)

Published by S. Karger AG, Basel
\end{abstract}

\section{Introduction}

Granular cell tumors (GCTs) have drawn attention over the past century due to their seemingly ubiquitous distribution throughout the body. The widespread distribution of 
these tumors raised questions regarding their origin. The original light microscopy findings have been augmented more recently with those from electron microscopy and the use of a growing array of immunohistochemical markers [1, 2]. Whereas Abrikossoff [3] originally claimed a smooth muscle origin for these tumors, the use of newer methods has revealed that they likely originate from Schwann cells.

The clinical presentation, gross endoscopic findings, and histology of GCTs in the gastrointestinal (GI) tract have previously been described in case studies $[1,4,5]$. The range of associated symptoms includes abdominal pain, diarrhea, constipation, rectal prolapse, fecal incontinence, hematochezia, and fecal occult blood. However, many patients have no symptoms at all and the tumors are found during routine colon cancer screening. Although GCTs have been identified in patients who have undergone endoscopy for such symptoms, it is unlikely that these lesions are the cause of that presentation.

In general, GCTs have been described as submucosal, white to yellowish-white tumors mostly less than $15 \mathrm{~mm}$ in size, but they can be up to $30 \mathrm{~mm}$ in diameter. These lesions can either cause overlying mucosal changes or be associated with normal-appearing mucosa [5, 6]. Most cases reported in literature describe isolated tumors, although there are some reports of multiple GCTs as well [7-9]. GCTs are typically immunopositive for S100 protein, vimentin, neuron-specific enolase, and sometimes for CD68 and nestin [1], and they are notably negative for chromogranin and $\alpha$-smooth muscle actin. On histology, GCTs exhibit moderate cellularity with areas of nesting separated by fibrous septa containing polygonal cells with round, small nuclei with few to no mitotic figures and abundant eosinophilic cytoplasm.

Approximately half of these tumors occur in the head and neck, though many other sites have also been reported $[10,11]$. However, there are very few reports of these tumors in the GI tract $[1,4-6,12]$. Within the GI system, esophageal GCTs are the most common, followed by tumors that occur in the colon $[1,6]$, particularly in the ascending colon and cecum $[4,5$, $13,14]$. Here, we report a rare case involving a female patient with a GCT directly on the ileocecal valve and discuss the management of this particular tumor type.

\section{Case Presentation}

A 42-year-old female with a history of pelvic pain and dysfunctional uterine bleeding had undergone an uncomplicated robot-assisted total laparoscopic hysterectomy. One year later, she presented with chronic lower abdominal pain worsening with defecation. Her symptoms began 7 months following the surgery, with transvaginal ultrasound showing no evidence of organic pathology as the cause of the pain. Diagnostic laparoscopy revealed only scarce adhesions which were lysed, and her pain began to improve thereafter. Four months later, she experienced an onset of loose stools with occasional hematochezia that lasted for 2 weeks, along with a return of abdominal pain and mild nausea without vomiting. A celiac disease panel including immunoglobulin $\mathrm{A}$ and tissue transglutaminase antibody resulted negative. She had no prior history of irritable bowel syndrome and underwent a colonoscopy for further evaluation of her symptoms and hematochezia. Two 9-mm sessile polyps were identified on the ileocecal valve (Fig. 1), which were resected with a hot snare. The biopsy results revealed tan-pink tissue containing epithelioid cells with ovoid nuclei and abundant granular cytoplasm. In addition, there was also evidence of spindling and pleomorphism, though with an absence of mitotic figures (Fig. 2a, b). Immunohistochemical staining was positive for S100, CD68, and inhibin alpha and with a Ki-67 proliferative index of 2-3\% (Fig. 
3). Periodic acid-Schiff staining with and without diastase was positive along with a tubular adenoma in the overlying mucosa (Fig. 2c). Given the high-risk features on pathology and since complete removal by endoscopic resection could not be ascertained with confidence (due to cautery artifacts), the patient was referred for right hemicolectomy. Pathologic review of a specimen from the right hemicolectomy showed no residual GCT or tubular adenoma. However, the patient continues to experience periodic chronic abdominal pain, implying that the GCT or the tubular adenoma of the ileocecal valve was not the cause of her symptoms.

\section{Discussion}

GCTs, including those in the GI tract, are mostly benign [1]. In the GI tract, most of these lesions can be removed by endoscopic resection. When endoscopic resection is not feasible, they can be removed surgically - or, for small lesions, close surveillance might be adequate $[7,15,16]$. However, the management becomes more complicated for tumors displaying patterns of atypia where the criteria for malignancy have not entirely been fulfilled but the risk of aggressive behavior is likely increased. The Fanburg-Smith criteria assess 6 histologic parameter: necrosis, spindling, vesicular nuclei with large nucleoli, increased mitotic activity, increased nuclear-to-cytoplasmic ratio, and pleomorphism. Neoplasms meeting 3 or more of these criteria are classified as malignant, those meeting 1 or 2 criteria as atypical, and those displaying only focal pleomorphism but meeting none of the other criteria are classified as benign. In a study of 73 patients, Fanburg-Smith et al. [17] found that cases with GCTs that display histologic atypia without meeting the criteria for malignancy did not lead to increased mortality, whereas $39 \%$ of the patients that did meet the histologic criteria for malignant GCT died within a median of 3 years. Certain factors may be independently associated with worse prognosis, such as the observance of cell spindling (as observed in our case); however, it seems that high-risk histologic characteristics need not always be present prior to metastasis [10]. Thus, the decision of whether to pursue surgical resection, endoscopy, or continued observation remains a difficult one when high-risk features are described by the pathologist.

In this case, the findings from the specimen were consistent with those of a GCT. However, high-risk features were also present upon histopathologic examination, and the tumor was classified as atypical. The management of the GCT in this case was not straightforward, as it is the first known reported GCT with high-risk features on the ileocecal valve. There was a case reported where a GCT was removed proximal to the ileocecal valve with an endoscopic snare, but whether any cellular atypia was present in this lesion is unclear [18]. Rex et al. [19], in their review of the quality of performance of colonoscopies, noted that in similar areas that are difficult to access or resect by endoscopy, surgical resection may be needed. However, their suggestion was with regard to adenomas, which likely have a higher risk of malignancy than GCTs. Lowe et al. [16] recommend endoscopic resection with strict followup, as malignant tumors normally reoccur locally within 1 year. Other authors suggest more conservative management with observation alone following biopsy, as the risk of complications from endoscopic resection are not justified in a setting of low risk for malignancy [1].

Of note in this case was the fact that the GCT displayed atypical features despite its small size, reinforcing the importance of close inspection of the ileocecal valve upon withdrawal of the scope. GCTs often do not involve the mucosal layer, and thus an atypical or malignant GCT could easily be missed. The atypical histologic features in our case were particularly 
Gapp et al.: Coexisting Granular Cell Tumor and Tubular Adenoma of the Ileocecal Valve

concerning and indicative of potentially aggressive tumor behavior. In addition, the GCT was associated with an overlying tubular adenoma, which is also rare and has only been described in gastric GCTs [20,21]. Although such pseudoepitheliomatous changes have been described previously, it is not known whether they reflect an increased predisposition to malignancy $[5,10]$. For these reasons, we chose to perform a hemicolectomy to ensure clear margins of resection.

In conclusion, we present a rare case of a GCT on the ileocecal valve coexisting with a tubular adenoma. This tumor type may be prone to oversight due to the anatomic and submucosal location. In addition, the overlying tubular adenoma and atypical histologic classification further complicated the management decisions. Additional case descriptions and management reports may help to establish a clearer clinical algorithm for the management of GCTs of the ileocecal valve or the ones coexisting with tubular adenomas.

\section{Statement of Ethics}

Patient consent was obtained. No ethics review was required.

\section{Disclosure Statement}

The authors declare that they have no conflict of interest.

\section{References}

1 Parfitt JR, McLean CA, Joseph MG, Streutker CJ, Al-Haddad S, Driman DK: Granular cell tumours of the gastrointestinal tract: expression of nestin and clinicopathological evaluation of 11 patients. Histopathology 2006;48:424-430.

-2 Fisher ER, Wechsler H: Granular cell myoblastoma - a misnomer. Electron microscopic and histochemical evidence concerning its Schwann cell derivation and nature (granular cell schwannoma). Cancer 1962;15:936-954.

3 Abrikossoff A: Über Myome. Virchows Arch 1926;260:215-233.

-4 Endo S, Hirasaki S, Doi T, Endo H, Nishina T, Moriwaki T, et al: Granular cell tumor occurring in the sigmoid colon treated by endoscopic mucosal resection using a transparent cap (EMR-C). J Gastroenterol 2003;38:385-389.

-5 Singhi AD, Montgomery EA: Colorectal granular cell tumor: a clinicopathologic study of 26 cases. Am J Surg Pathol 2010;34:1186-1192.

6 Johnston J, Helwig EB: Granular cell tumors of the gastrointestinal tract and perianal region: a study of 74 cases. Dig Dis Sci 1981;26:807-816.

7 Melo CR, Melo IS, Schmitt FC, Fagundes R, Amendola D: Multicentric granular cell tumor of the colon: report of a patient with 52 tumors. Am J Gastroenterol 1993;88:1785-1787.

-8 Fried KS, Arden JL, Gouge TH, Balthazar EJ: Multifocal granular cell tumors of the gastrointestinal tract. Am J Gastroenterol 1984;79:751-755.

-9 Saleh H, El-Fakharany M, Frankle M: Multiple synchronous granular cell tumors involving the colon, appendix and mesentery: a case report and review of the literature. J Gastrointestin Liver Dis 2009;18:475-478.

10 Ordóñez NG, Mackay B: Granular cell tumor: a review of the pathology and histogenesis. Ultrastruct Pathol 1999;23:207-222.

11 Lack EE, Worsham R, Callihan MD, Crawford BE, Klappenbach S, Rowden G, et al: Granular cell tumor: a clinicopathologic study of 110 patients. J Surg Oncol 1980;13:301-316.

12 Rossi GB, de Bellis M, Marone P, De Chiara A, Losito S, Tempesta A: Granular cell tumors of the colon: report of a case and review of the literature. J Clin Gastroenterol 2000;30:197-199.

13 Sultan MI, Suchi M, Werlin SL: Cecal granular cell tumor. J Pediatr Gastroenterol Nutr 2011;52:375. 
Gapp et al.: Coexisting Granular Cell Tumor and Tubular Adenoma of the Ileocecal Valve

14 Sohn DK, Choi HS, Chang YS, Huh JM, Kim DH, Kim DY, et al: Granular cell tumor of colon: report of a case and review of literature. World J Gastroenterol 2004;10:2452-2454.

15 Lee SR, Park EB: Granular cell myoblastoma of the cecum: report of a case. Korean J Gastrointest Endosc 1983;3:103-107.

-16 Lowe DL, Chaudhary AJ, Lee JR, Chamberlain SM, Schade RR, Cuartas-Hoyos U: Four cases of patients with gastrointestinal granular cell tumors. South Med J 2007;100:298-301.

17 Fanburg-Smith JC, Meis-Kindblom JM, Fante R, Kindblom LG: Malignant granular cell tumor of soft tissue: diagnostic criteria and clinicopathologic correlation. Am J Surg Pathol 1998;22:779-794.

18 Park NY, Kim KJ, Kim YJ, Roh JH, Im DG, Nam JH, et al: A case of granular cell tumor of the colon treated by colonoscopy. Korean J Gastrointest Endosc 2006;32:67-70.

19 Rex DK, Bond JH, Winawer S, Levin TR, Burt RW, Johnson DA, et al: Quality in the technical performance of colonoscopy and the continuous quality improvement process for colonoscopy: recommendations of the US Multi-Society Task Force on Colorectal Cancer. Am J Gastroenterol 2002;97:1296-1308.

20 Yamaguchi K, Maeda S, Kitamura K: Granular cell tumor of the stomach coincident with two early gastric carcinomas. Am J Gastroenterol 1989;84:656-659.

21 Schwartz DT, Gaetz HP: Multiple granular cell myoblastomas of the stomach. Am J Clin Pathol 1965;44:453-457.

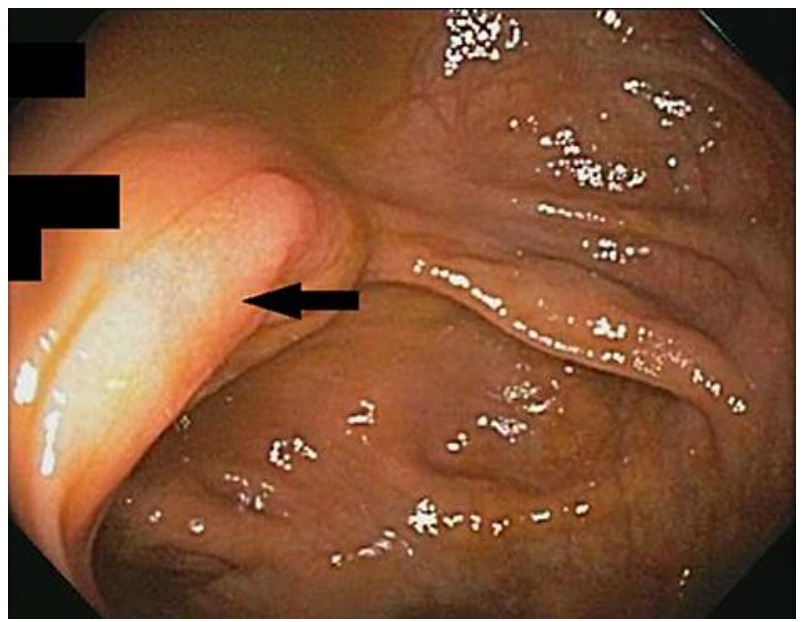

Fig. 1. Endoscopic image of a granular cell tumor located on the cecal valve (black arrow). 

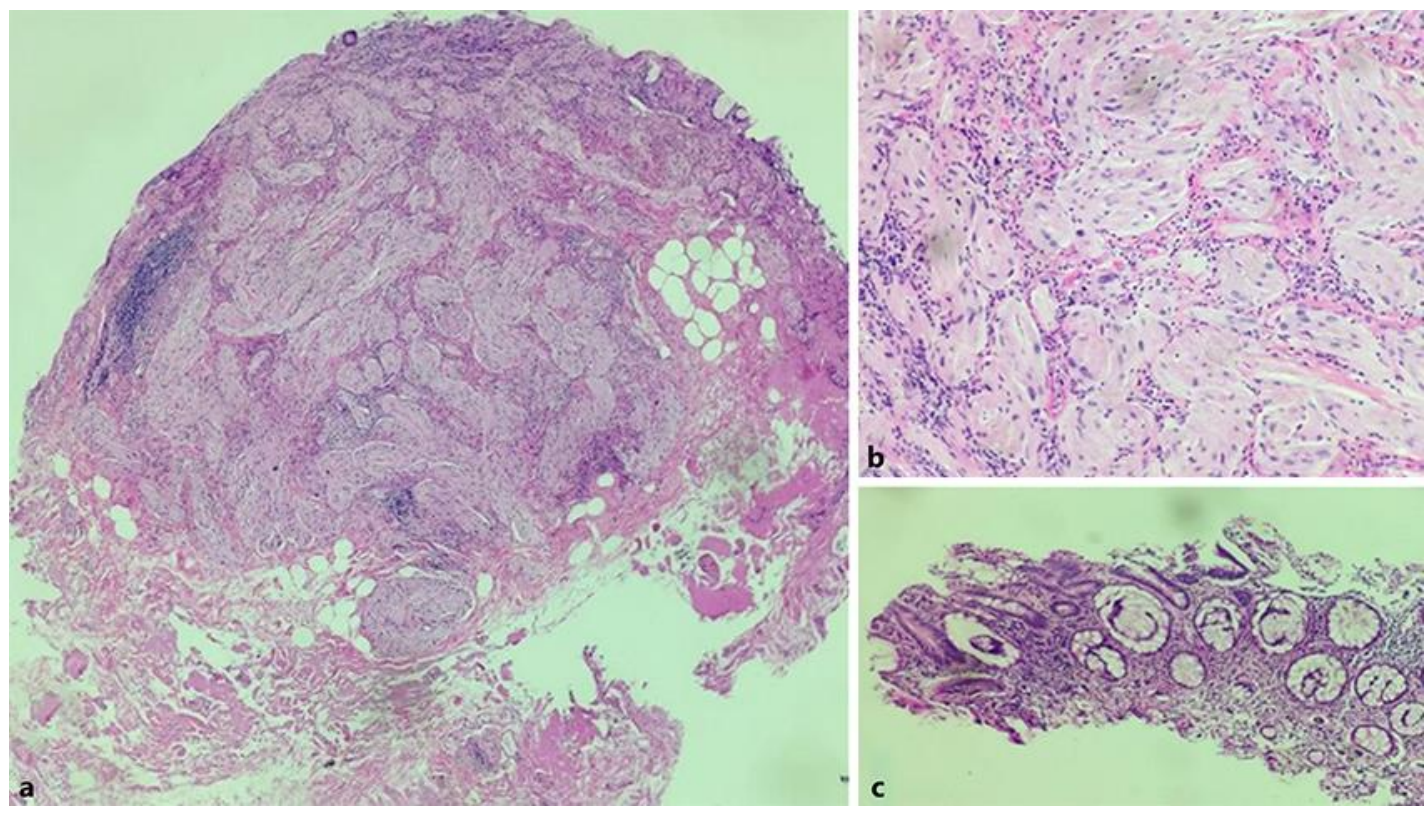

Fig. 2. Histopathologic images of a granular cell tumor by hematoxylin and eosin staining that is primarily submucosal with some focal mucosal extension (a). It is composed of compact nests of epithelioid cells with oval nuclei including abundant, granular cytoplasm with spindling and moderate nuclear pleomorphism. Mitotic figures are not identified (b). A small cauterized fragment of a tubular adenoma is overlying the granular cell tumor (c), with unknown clinical significance.
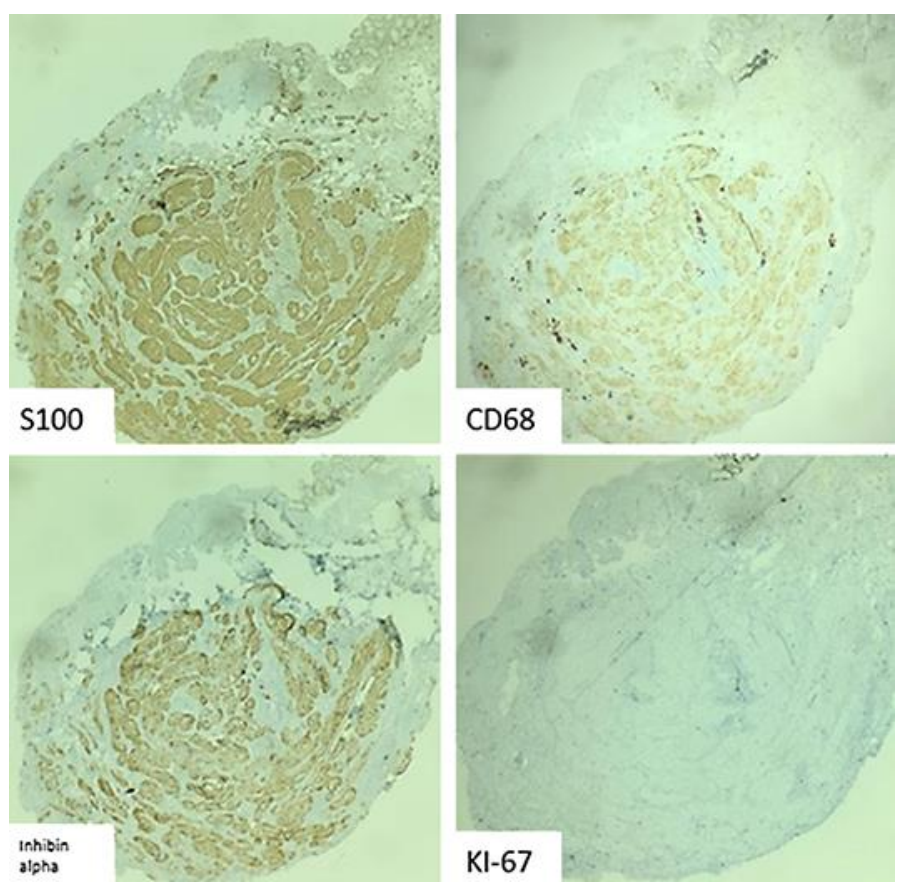

Fig. 3. Immunohistologic staining positive for S100, CD68, and inhibin alpha. The Ki-67 index was 2-3\%. This immunophenotype is in accordance with the histopathologic findings and is consistent with granular cell tumor with atypical features. 